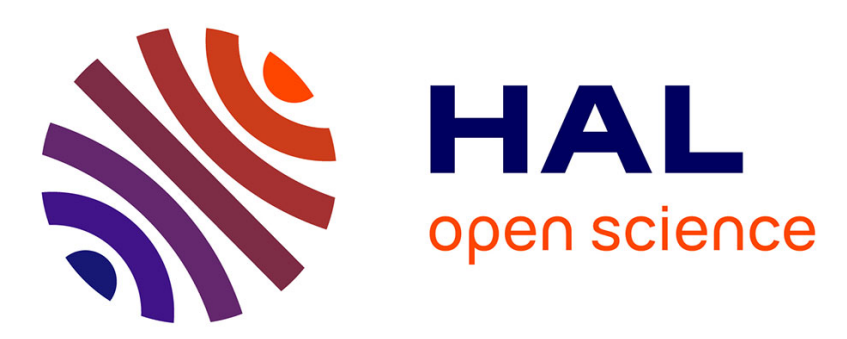

\title{
Evaluation and Redesign of a Curriculum Framework for Education About Game Accessibility
}

Thomas Westin, Jérôme Dupire

\section{To cite this version:}

Thomas Westin, Jérôme Dupire. Evaluation and Redesign of a Curriculum Framework for Education About Game Accessibility. 15th International Conference on Entertainment Computing (ICEC), Sep 2016, Wien, Austria. pp.217-222, 10.1007/978-3-319-46100-7_20 . hal-01640292

\section{HAL Id: hal-01640292 \\ https://hal.inria.fr/hal-01640292}

Submitted on 20 Nov 2017

HAL is a multi-disciplinary open access archive for the deposit and dissemination of scientific research documents, whether they are published or not. The documents may come from teaching and research institutions in France or abroad, or from public or private research centers.
L'archive ouverte pluridisciplinaire HAL, est destinée au dépôt et à la diffusion de documents scientifiques de niveau recherche, publiés ou non, émanant des établissements d'enseignement et de recherche français ou étrangers, des laboratoires publics ou privés.

\section{(c)(1)}

Distributed under a Creative Commons Attribution| 4.0 International License 


\title{
Evaluation and Redesign of a Curriculum Framework for Education About Game Accessibility
}

\author{
Thomas Westin ${ }^{1}$ and Jerome Dupire ${ }^{2}$ \\ ${ }^{1}$ Stockholm University, Department of Computer and Systems Science, Kista, Sweden \\ thomaswedsv.su.se
}

${ }^{2}$ CNAM / CEDRIC 292, rue St Martin, 75003 Paris, France

dupire@enam. fr

\begin{abstract}
Game Accessibility (GA) has been brought to the front of the video game landscape thanks to a recent but major change in the US law called the Communications and Video Accessibility Act; GA is now a legal obligation for game developers in the US. However, there is a gap between legislation and practice of GA. This study is based upon a previous tentative curriculum framework (TCF) for GA. The questions are: What are the opinions among educators and game developers regarding the TCF? How could the TCF be redesigned? To answer the questions, the TCF was surveyed with practitioners and researchers in the GA community. This paper presents an evaluation and redesign of the TCF, divided into different categories, depending on the students' profiles, scopes and skills. Furthermore, how the curriculum content can be created and shared is also discussed, as well as future work.
\end{abstract}

Keywords: Game Accessibility $\bullet$ Game Education $\bullet$ Curriculum Framework

\section{Introduction}

Game accessibility (GA) has been researched since the dawn of the computer and video game industry and there is a significant amount of publications, see e.g. [1, 2]. However, only a limited number of titles from the mainstream game industry offer even basic accessibility features. In the USA, the Communications and Video Accessibility Act (CVAA) [3] is about to change this situation: game consoles and distribution platforms now have to be accessible and, from January 2017, game software also has to be accessible. As USA is one of the largest markets for games in the world, the CVAA have already had international impact; two of the major game consoles were patched with accessibility features for the first time in 2015 .

adfa, p. 1, 2011 .

(C) Springer-Verlag Berlin Heidelberg 2011 
However, if these legal provisions are genuine progress and recognition, there is still a gap between the aims and the means. Indeed, game accessibility is still not an identified part of the video game curriculum around the world and students are often not aware of game accessibility at all. This study is a follow-up on a tentative curriculum framework (TCF) [4], defined as a "modular structure that support creating and sharing educational resources, as well as teaching and learning about game accessibility" [4]. In the framework learning outcomes were related to three outcome requirement levels: 1) Introduced (I) outcomes are not examined, i.e. the outcome does not have to be part of an assignment but could be included in some lecture or reading material; 2) Transitional (T) outcomes may be examined, optional by the course designer, where the student may have to show that s/he has acquired knowledge, skills and/or attitudes; and 3) Emphasized (E) outcomes have to be examined, required to pass the course; the examination is focused on the complex integration of knowledge, skills and attitudes regarding the learning outcome. The requirement levels were adapted from [5]. As the TCF was an interpretation of results in the first study, the research questions in this follow-up study are: What are the opinions among educators and game developers regarding the TCF? How could the TCF be redesigned?

\section{Method}

An online survey based on the tentative curriculum framework [4] was sent for evaluation to 1) twenty-three persons who answered the survey in the first study [4] and agreed to participate in this follow-up study; 2) fifteen participants at the IGDA Game Accessibility SIG Roundtable at Game Developers Conference 2016; and 3) two others who had actively asked to be included. In total, the survey in this paper was sent to forty people, of which one e-mail address bounced, and sixteen persons responded within two weeks' time. The survey ${ }^{1}$ was mainly composed of closed questions to minimize time required to fill it in. People were asked to say if they agreed, disagreed or did not know, about each learning outcome and the relation to requirement levels (I, T, E) in the curriculum framework. The questions were repeated for each category (designer basic, engineer basic, and advanced levels). Open questions allowed them to share any comment about their choices for each category, as well as a final generic question about the study. In contrast to the first study, this follow-up study required each respondent to fill in their name and e-mail, in case we needed some further clarification of their answers. This may have affected the number of responses.

\section{$3 \quad$ Results and Analysis}

First, some interesting suggestions appeared in the open text fields, such as inviting impaired people during a course in order to see and understand what their real situation is regarding video games and/or the environment. Another respondent reflected upon the implications of doing this in practice "because of logistical complexity". Still, a

\footnotetext{
${ }^{1}$ https://goo.gl/r514LU
} 
suggestion could be to try and perform some participatory design at least once during a curriculum.

\subsection{Basic Level for Designers}

Most respondents (13 of 16) considered history important for designers. All (16 of 16) agreed that introduction of scope of issues, a transitional outcome of know-how of solutions, and emphasis on basic concepts and needs of disabled was adequate. Interestingly, one respondent disagreed to put emphasis on design methods for designers, while the others (15/16) agreed. Only 6/16 agreed that introduction of funding was important and $11 / 16$ agreed that legislation was important. Almost all $(15 / 16)$ agreed that experience of disability was important.

The quantitative data were confirmed by quotes from the open questions. For instance, scope of the issues but also experience of disabilities were clearly supported: "The key at a basic level is to emphasize the issue, to make it personal". Also, the disagreement but also uncertainty (don't know) regarding funding was clearly expressed: "To be aware of the cost of providing accessibility is more relevant in my opinion". Furthermore, regarding legislation and funding: "Areas around legalisation $\&$ funding are very country dependent. Games are multi-national. The issues are multinational.". Funding was included in the survey due to the commercial nature of computer games, and legislation was motivated by international impact of the CVAA. Another reply reflects on the process of learning from basic to advanced levels: "Awareness of legislation and funding are important, but seem like they might work better as material that is covered toward the end of the curriculum". Finally, a comment regarding history of game accessibility: "History is important, but maybe provided anecdotally throughout. Perhaps it could be emphasized alongside legislation and funding". A suggestion may be to merge these learning outcomes with related topics.

\subsection{Basic Level for Engineers}

Two learning outcomes were agreed by the same number of respondents as for designers: issues (16/16) and funding (6/16). Six learning outcomes had similar numbers of agreements as for designers: legislation (12/15), experience (14/16), know-how $(15 / 16)$, basic concepts $(14 / 16)$, needs $(13 / 16)$, and design methods $(13 / 16)$. Interestingly, more respondents agreed that history was important for designers $(13 / 16)$ than for engineers (9/16). This may be better understood based on this comment: "Proper execution of the design is important, so knowing what the issues are and also the proper solutions seem to be the most important.". One respondent suggested that if engineers know the issues and follow the design by designers who are aware of e.g. history, it may be enough. However, this may also be viewed as too focused on utility alone.

\subsection{Advanced Level for Designers and Engineers}

The advanced level contains two less learning outcomes than the basic level; the items basic concepts and needs of disabled are supposed to be part of the basic level courses 
and thus, do not appear here. Most of the respondents agreed about the relevance of all seven learning outcomes. However, one respondent said: "Legalisation \& Funding is a non-issue for design \& engineer". Still, while legislation is only formally relevant in countries with legislation for game accessibility, funding is needed for all professional game developers. Furthermore, for smaller, independent developer teams, there may not be a specific in-house person to manage legislative issues, which may make this relevant for both engineers and designers at the advanced level. It would be interesting to discuss these particular learning outcomes more with professionals in the game industry.

\section{Discussion}

The framework builds upon eight components in the UNESCO toolkit of curriculum design [6]. The framework focuses on three of these as explained in [4], represented by sections 4.1-4.3 below.

\subsection{Broad Learning Objectives and Outcomes}

The main goal of the framework is to raise awareness about game accessibility among both professional and aspiring game developers. Based on the UNESCO toolkit [6] overall objectives and outcomes are knowledge, understanding, skills, values and attitudes. These are represented by the names of learning outcomes in Table 1, either directly (e.g. 'know the scope', 'understand basic concepts') or indirectly (e.g. 'knowhow', 'able to apply', which implies skills). To change values and attitudes may require longer time and should thus be an integral part of all learning outcomes. Still, to gain experience of disabilities through various forms of simulations and participatory design may have a more direct relationship to changing values and attitudes.

\subsection{Structure of the Curriculum Content, Learning Areas and Subjects}

According to UNESCO [6] the framework should describe the structure of content, as well as the subject or learning areas. A brief description of each learning area, presented as outcomes in Table 1 is: 1) Basic concepts are e.g. disability, accessibility and universal design; 2) Needs of disabled are grounded in research involving people with disabilities; 3) Design methods describe how games can be made more accessible; 4) The scope describe the relevance of issues; 5) Experience of disabilities aims to change values and attitudes by gaining empathy through e.g. simulating disabilities; 6) Knowhow of solutions is how to practically implement game accessibility. Given the varied opinions about history, funding and legislation, those are now integrated as optional parts of needs and scopes outcomes (Table 1). One option is to cover these subjects as side literature or further readings, another is to have them part of the curriculum with examination, based upon the goals of a specific course. If there is no basic level course, then concepts and needs should also be included in the advanced level, which is why $\mathrm{E}$ is marked with a parenthesis: $(\mathrm{E})$. 
For instance, a game designer who wants to learn the basics and validate the competence must only learn basic concepts, needs of disabled and be able to apply design methods. An engineer can do the same but switch design methods with know-how of solutions. The advanced level is the most flexible. Any advanced student, who has passed a basic level course, can ignore the basic concepts and needs of disabled. Furthermore, an advanced game designer who has taken the basic level course must only learn the scope of issues and know-how of solutions. An advanced engineer who has taken the basic level course needs learn the scope of issues, but also design methods. This enables an advanced level student to fill the gap between basic level designers and engineers as they have insights into both design methods and implementation of designs (or solutions).

Table 1: Redesigned curriculum framework. Modifications marked in italic text.

\begin{tabular}{|c|c|c|c|}
\hline $\begin{array}{l}\text { Learning outcomes } \\
\text { - in arbitrary order }\end{array}$ & $\begin{array}{l}\text { Basic level } \\
\text { - for Designers }\end{array}$ & $\begin{array}{l}\text { Basic level } \\
\text { - for Engineers }\end{array}$ & $\begin{array}{l}\text { Advanced level } \\
\text { - for all }\end{array}$ \\
\hline 1. Understand basic concepts & $\mathrm{E}$ & $\mathrm{E}$ & $(E)^{2}$ \\
\hline 2. Know the needs of disabled ${ }^{3}$ & $\mathrm{E}$ & $\mathrm{E}$ & $(E)^{2}$ \\
\hline 3. Able to apply design methods & $\mathrm{E}$ & $\mathrm{T}$ & $(E)^{4}$ \\
\hline 4. Know the scope of issues ${ }^{5}$ & I & I & $\mathrm{E}$ \\
\hline 5. Experience of disabilities & I & I & $\mathrm{T}$ \\
\hline 6. Know-how of solutions & $\mathrm{T}$ & $\mathrm{E}$ & $(E)^{4}$ \\
\hline
\end{tabular}

It is important that the framework is modular, to be flexible and applicable for both students and autodidacts working in the game industry. The redesigned framework (Table 1) does not say in which order the various learning outcomes should be addressed at each level. It does have a progression from basic to advanced levels regarding the three outcome requirement levels (introduced, transitional, and emphasized). However, the learner could take an advanced level course without having to take the basic level course, although the course will then naturally be harder and take longer time. Furthermore, to learn the basics, the introductory and transitional level outcome requirements could also be ignored, as those are not (required to be) examined.

\subsection{Standards of Resources Required for Implementation}

As the curriculum framework aims to provide a structure for sharing and creating Open Educational Resources (OERs), there must be proper acknowledgement and use of the content. Furthermore, all the content must be easy to find based upon user profile, e.g. designers / engineers / advanced, teacher / student qualifications etc. The resources have

\footnotetext{
${ }^{2}$ Include only in advanced level if there is no prerequisite basic level course

${ }^{3}$ May also include game accessibility history and legislation where applicable

${ }^{4}$ Include only if it has not been emphasized at the basic level

${ }^{5}$ May also include awareness of funding and economic issues for both developers and gamers
} 
also to be accessible according to $\mathrm{W} 3 \mathrm{C}$ presentation [7] and web content [8] accessibility guidelines. The community of educators must agree upon which standards to use and to what extent, in collaboration with disabled. All formats of OERs must be editable and have support for accessibility, as far as possible. To implement the framework a number of Open Educational Resources (OERs) have to be developed by the community of educators in games. An important part is to map out the types of resources which look to be the more suitable and/or usable, regarding the different learning outcomes. Matching between each learning outcome and the most relevant or usable types of resources is also necessary.

\section{$5 \quad$ Conclusions and Future Work}

Based upon the opinions of respondents, we have confirmed the design of the tentative curriculum framework presented in [4] with some modifications (Table 1). To put the redesigned framework into practice, various existing and future resources can be mapped to learning outcomes, as discussed in section 4.3. Future work is to investigate what formats and licenses to use for OERs that can be accepted by all educators, be most useful for game developers and students, and be as accessible as possible. We will build different use cases in an online deposit and design the corresponding interfaces and architecture, before evaluating their usability and efficiency. This needs to be done in collaboration with both game industry, academia and disability organizations.

\section{References}

[1] B. Yuan, E. Folmer, and F. Harris, "Game accessibility: a survey," Universal Access in the Information Society, vol. 10, pp. 81-100, 2011.

[2] T. Westin, K. Bierre, D. Grammenos, and M. Hinn, "Advances in Game Accessibility from 2005 to 2010," in HCI International, Orlando, USA, 2011, pp. 400-409.

[3] FCC. (n.d., 2016-01-04). FCC Extends ACS Waiver for Video Game Software. Available: https://www.fcc.gov/document/fcc-extends-acs-waiver-videogame-software

[4] T. Westin and J. Dupire, "Design of a curriculum framework for raising awareness of game accessibility," in ICCHP, Linz, Austria, 2016.

[5] P. L. Maki, Assessing for learning: buidling a sustainable commitment across the institution, 2 ed.: Stylus Publishing, 2010.

[6] UNESCO. (n.d., 2016-01-10). Curriculum Design. Activity 1: The structure of a curriculum framework. Available: http://www.ibe.unesco.org/fileadmin/user_upload/COPs/Pages_documents/R esource_Packs/TTCD/sitemap/Module_3/Module_3_1_concept.html

[7] W3C. (n.d., 2015-09-02). W3C Presentation guidelines. Available: http://www.w3.org/WAI/training/accessible

[8] W3C. (n.d., 2016-05-04). Web Content Accessibility Guidelines (WCAG) Overview. Available: https://www.w3.org/WAI/intro/wcag 